\title{
Authors' reply: Measles on the cruise ship: links with virus spreading into an emergency department in Southern Italy
}

S Lanini ${ }^{1}$, M R Capobianchi (maria.capobianchi@inmi.it) ${ }^{2}$, M G Pompa ${ }^{2}$, L Vellucci²

1. National Institute for Infectious Diseases (INMI) 'Lazzaro Spallanzani’ Rome, Italy

2. Ministry of Health, Directorate General for Prevention, Rome, Italy

\section{To the Editor:}

We thank Cozza et al. for their letter in response to our paper [1]. The letter is a timely report and a good opportunity to provide additional information about the outbreak and share some general considerations.

The Italian Ministry of Health has to date identified 29 confirmed cases of measles that occurred between 20 February and 10 March 2014 on the cruise ship in question. Of them, 23 were crew members and six were Italian passengers (data for non-Italian passengers are not available). These include three cases in addition to those reported before [2], one passenger with disease onset on 27 February and two crew members with onset on 1 and 10 March. Seven of the 29 confirmed cases developed symptoms at home after returning from the cruise. These cases included a young child (passenger) from Lazio, a young child (passenger) from Umbria, an adult passenger from Sardinia who needed admission to an intensive care unit, two cases from Lecce (an adult passenger and a crew member), an adult passenger from Bari, and the teenage passenger from Brindisi reported by Cozza et al [1].

The temporal distribution of symptom onset suggests that most cases may have been exposed to the same source of infection between 8 and 13 February 2014. In fact, 28 of the 29 cases clustered between 20 February and 1 March; this time frame is shorter than the maximum of 14 days expected after a simultaneous exposure, the minimum and maximum expected incubation time for measles being seven and 21 days, respectively $[4,5]$. The hypothesis of a unique source of infection is also supported by the results of molecular investigation which identified a single molecular variant in all infected patients who underwent phylogenetic analysis [2].

As we could not find any obvious common exposure on board, it is likely that 28 subjects may have been infected ashore while visiting one of the places where the ship stopped, i.e. Savona on 8 February, Marseille on 9 February, Barcelona on 10 February, Palma 11 February, or Civitavecchia on 13 February; on 12 February, the ship was at sea. In contrast, the case that occurred on 10 March is likely to have been infected on board. Molecular characterisation of the viral strains circulating in these locations within the first half of February will further clarify this point.

Cozza et al. raised another interesting issue with relevant public health implications: the contact tracing investigation pointed out that 12 of all 32 potential measles cases from Puglia were associated with exposure to measles within an emergency department [1]. Media news report that the Department of Health in Spain is investigating a large, still ongoing, measles outbreak in Catalonia, with about 102 cases in the first three months of 2014 [3]. It is noteworthy that about $24 \%$ of all reported cases in Catalonia occurred among healthcare workers [3]. Healthcare settings may play an important role both in spreading and in controlling respiratory infections. In particular, emergency departments may represent a significant site of transmission for respiratory pathogens due to close contact between cases and susceptible subjects, both patients and healthcare workers [6]. The experience from Puglia and the information provided by the Spanish Department of Health suggest that there is still a need to implement better procedures for infection control in emergency departments in Europe.

References

1. Cozza V, Chironna M, Leo C, Prato R. Letter to the editor: Measles on the cruise ship: links with virus spreading into an emergency department in Southern Italy. Euro Surveill. 2014;19(19): pii=20800. Available from: http://www. eurosurveillance.org/ViewArticle.aspx?Articleld $=20800$

2. Lanini S, Capobianchi M, Puro V, Filia A, Del Manso M, Kärki T, et al. Measles outbreak on a cruise ship in the western Mediterranean, February 2014, preliminary report. Euro Surveill. 2014;19(10):pii=20735. http://dx.doi. org/10.2807/1560-7917.ES2014.19.10.20735

3. Salud confirma 102 casos sarampión primer trimestre 2014, el $24 \%$ sanitarios. [Department of Health confirms 102 cases of measles in the first trimester of $2014,24 \%$ of which among healthcare workers]. Barcelona: La Vangardia; 8 Apr 2014. 
Spanish. Available from: http://www.lavanguardia.com/ vida/20140408/54404825803/salud-confirma-102-casossarampion-primer-trimestre-2014-el-24-sanitarios.html

4. Fitzgerald TL, Durrheim DN, Merritt TD, Birch C, Tran T. Measles with a possible 23 day incubation period. Commun Dis Intell Q Rep. 2012;36(3):E277-80.

5. Heymann DL. Control of Communicable Diseases Manual. 19th ed. Washington DC: American Public Health association; 2008.

6. Puro V, Fusco FM, Lanini S, Nisii C, Ippolito G. Risk

management of febrile respiratory illness in emergency departments. New Microbiol. 2008;31(2):165-73. 